\title{
The effects of birth order on locus of control
}

\author{
DONALD A. WALTER and CINDY A. ZIEGLER \\ University of Wisconsin-Parkside, Kenosha, Wisconsin 53140
}

\begin{abstract}
Nine-year-old children were used in examination of the effects of birth order on locus of control. It was found that both the first born and the last born in families of three siblings or more had a more external locus of control than middle-born children. In addition, last-born children were more external in large families. It is probable that failure of previous studies to agree on similar effects was due to differences in the number of siblings for subjects used in the sample.
\end{abstract}

In general, an external locus of control, the feeling that events are not under an individual's control, is thought to be largely the result of parental attention in childhood. A child receiving a great deal of parental attention looks to social approval for support rather than to himself, and this results in the development of a more external locus of control than children not receiving parental attention would have. First-born children receive more direct parental attention than later born, who must compete with siblings for such attention (Lasko, 1954; Sears, 1950) and are accordingly thought to develop a more external locus of control.

Studies using adult subjects have shown mixed support for this assertion. Eisenman and Platt (1968), Moran (1967), and Warren (1966) have concluded that first-born adults are more susceptible to social pressures and therefore more dependent than are later born, but Crandall, Katkovsky, and Crandall (1965) and MacDonald (1971) claim just the opposite. Schildhaus (1974), using children as subjects, found that first-born children have a high need for social approval and a more external locus of control, whereas the opposite is true for later borns. Newhouse (1974), on the other hand, found no significant locus-of-control difference between first- and later-born 9- to 10-year-old children.

In these studies the number of siblings in families from which children were selected varied widely. For example, in the MacDonald (1971) study, most firstand later-born children were from two-sibling families; very few were from larger families. Newhouse (1974) and Schildhaus (1974), in contradictory studies, used some larger families, but both reported scores only for first- and later-born groups. Thus, any birth-order effects in later-born children were left untested. This is unfortunate, for there is reason to suspect that last-born children in large families might have a more external locus of control (due to parental attention) than middleborn children. This study examines this possibility by separating relatively large sibling groups into first-, middle-, and last-born groups rather than first- and laterborn groups.

\section{METHOD}

\section{Subjects}

Fifteen each first-born, middle-born, and last-born 9-yearold elementary students of both sexes were randomly selected from three elementary schools in white middle-class suburbs of Milwaukee, Wisconsin. All children were drawn from families of three children or more. The mean number of children (including the subject) in each group was $4.2,4.5$, and 3.7 , respectively, and the number of males was 7,6 , and 8 , respectively.

\section{Materials}

The Bailer (1961) childrens' locus-of-control scale consists of 23 yes-no questions suited to assessing locus of control from the perspective of children. An example of a question is "Can a child of your age ever have his own way?" A greater number of "yes" answers on this scale indicates a more internal locus of control.

Design

A randomized three-group design was used, with birthorder position constituting the three levels of the independent variable. Children were first born, middle born (all middle positions were treated as equal), or last born.

\section{Procedure}

The 45 subjects were drawn from three separate classrooms and were administered the Bailer locus-of-control questionnaire in three separate sessions. Children were given a blank answer sheet on which they wrote their name, ordinal birth position, and number of brothers and sisters. They were told that they were not being tested but were being given a questionnaire to find out about their feelings about different events in their lives. They were then read each item on the locus-of-control questionnaire (from 1 to 23 ) and asked to write a "yes" or "no" answer depending on how they felt about the question. Any question that required repeating for any child was read again. The entire testing procedure took approximately $10 \mathrm{~min}$ for each class.

\section{RESULTS}

The mean number of "yes" responses for each of the birth-order groups served as the data for a one-way analysis of variance. Significant differences were found between groups $[F(2,42)=12.32, p<.01]$. The mean locus-of-control scores (number of "yes" responses) were $11.9,16.3$, and 13.7 for first-, middle-, and last- 
born children, respectively. A contrast analysis with middle-born children opposing first- and last-born children yielded a significant contrast effect $[F(1,42)=$ $29.43, p<.01$ ], showing middle-born children to be more internal than both first- and last-born children.

\section{DISCUSSION}

The results of this study support the notion that first-born children have a more external locus of control than later-born brothers and sisters, but with some qualifications. The difference is most substantial between first and middle born, and the latter tend to be more internal than either first or last born. Some explanation for differences between the studies of Newhouse (1974) and Schildhaus (1974) is suggested by this pattern. Both authors used some families of three siblings. However, comparisons were made only between first born and later born, a group sometimes consisting of both middle- and last-born children. It is probable that the sample used by Schildhaus contained a larger proportion of three-sibling families than that used by Newhouse, for a greater proportion of middleborn children included in the later-born group should cause greater apparent differences in locus of control between first and later born.

This study used relatively large families. The mean number of siblings was 4.1, and some large (6-sibling) families were included. It is probable that in large families locus-of-control effects in the last born as well as in the first born could be attributed to parental attention. There is no direct evidence for this assertion, but it is consistent with an analysis of locus of control as a function of the number of siblings. If parental attention is more pronounced in large families, it should be reflected in locusof-control scores for last-born children. A product-moment correlation of -.253 was found between the locus-of-control scores for last-born children and family size, showing that lastborn children from large families are somewhat more external than those from smaller families. Similar correlations for first- and middle-born children were essentially 0 ( $\mathrm{rs}=-.03$ and .05 , respectively).

In summary, middle-born children in families of three or more were found to have a more internal locus of control than their first-born or last-born siblings. This is commonly attributed to parental attention during rearing and offers a possible explanation for contradictory findings in previous research on birthorder/locus-of-control effects.

\section{REFERENCES}

BAILER, I. Conceptualization of success and failure in mentally retarded and normal children. Journal of Personality, 1961, 29, 303-320.

Crandall, V., Katkovsky, W., \& Crandall, V. J. Children's beliefs in their own control of reinforcements in intellectualacademic achievement situations. Child Development, 1965, 36, 91-109.

Eisenman, R., \& Platt, J. Birth order and sex differences in academic achievement and internal-external control. Journal of General Psychology, 1968, 78, 279-285.

LAsкo, J. Parent behavior toward first and second children. Genetic Psychology Monographs, 1954, 49, 97-137.

MacDonald, A. Birth order and personality. Journal of Consulting and Clinical Psychology, 1971, 36, 171-176.

Moran, G. Notes and comments: Ordinal position and approval motivation. Journal of Consulting Psychology, 1967, 31, 319-320.

Newhouse, R. Locus of control and birth order in school children. Journal of Clinical Psychology, 1974, 30, 364-365.

Schildhaus, D. The role of ordinal position in the psychological development of children. Unpublished master's thesis, Columbia University, 1974.

SeARS, R. Ordinal position in the family as a psychological variable. American Sociological Review, 1950, 15, 397-410.

Warren, J. Birth order and social behavior. Psychological Bulletin, 1966, 65, 39-49.

(Received for publication March 8, 1980.) 